\title{
¿DISMINUCIÓN DE LA POBREZA EN MÉXICO? ESTUDIO DE CASO PARA QUINTANA ROO 2010-2016
}

POVERTY REDUCTION IN MEXICO? CASE STUDY FOR QUINTANA ROO 2010-2016

\author{
Miguel Angel Barrera Rojas \\ División de Ciencias Políticas y Humanidades \\ Universidad de Quintana Roo \\ Chetumal, Quintana Roo, México \\ Miguel.barrera@ugroo.edu.mx
}

Fecha de recepción: 26/09/2019 - Fecha de aprobación: 16/12/2019

\section{RESUMEN}

Este trabajo evalúa la cuestión de la pobreza en Quintana Roo, México para el periodo 2010-2016. Se cuestiona si la disminución de la pobreza que el gobierno federal del presidente Enrique Peña Nieto aseveró como verídica es en realidad una mejora en las condiciones de vida y de ingreso, o si dicha disminución tiene lugar a partir únicamente de los criterios con los que se operacionaliza la pobreza. Para ello se hizo trabajo documental en dos partes: Primero una revisión y análisis de los Lineamientos y Criterios para la Definición, Identificación y Medición de la Pobreza que aparecen en el Diario Oficial de la Federación; y segundo, análisis de los datos sobre carencias e ingresos que el Consejo Nacional de Evaluación de la Política de Desarrollo Social (CONEVAL) y el Instituto Nacional de Estadística Geografía e Informática (INEGI) ofrecen para 2010-2015 y 2010, 2012, 2014 y 2016, respectivamente. Entre los resultados más importantes, se pueden mencionar que en efecto, las carencias promedio de los hogares en Quintana Roo disminuyeron, sin embargo, los ingresos en 2016 permanecieron en condiciones similares a los de 2010, es decir, la disminución de la pobreza extrema se puede atribuir solo a la intervención del Estado a través de la creación de infraestructura y no de la efectividad de sus políticas económicas.

PALABRAS ClAVE: Pobreza; Pobreza Extrema; Política Social; Medición de la Pobreza; Quintana Roo.

\section{ABSTRACT}

This paper evaluates the status of poverty in Quintana Roo, Mexico for the period 20102016. The research question that supports this paper is whether the decrease in extreme poverty and poverty that the federal government of president Enrique Peña Nieto asserted as real is actually an improvement in living and income conditions, or if said decrease takes place

\footnotetext{
“Visión de Futuro" Año 17, Volumen N 24 N¹, Enero - Junio 2020 - Pág. 193 - 215

URL de la Revista: http://visiondefuturo.fce.unam.edu.ar/index.php/visiondefuturo/index

URL del Documento: http://visiondefuturo.fce.unam.edu.ar/index.php/visiondefuturo/issue/view/17

ISSN 1668 - 8708 - Versión en Línea

E-mail: revistacientifica@fce.unam.edu.ar
} 
at based solely on the criteria with which poverty is defined and measured. To this end, cabinet work was carried out in two parts: The first was a review and analysis of the Guidelines and Criteria for the Definition, Identification and Measurement of Poverty that appear in the Official Gazette of the Federation; and the second in the analysis of the data on deprivation and income that the National Council for the Evaluation of Social Development Policy (CONEVAL) and the National Institute of Statistics, Geography and Informatics (INEGI) offer for 2010-2015 and 2010, 2012, 2014 and 2016, respectively. Among the most important results, it can be mentioned that, in effect, the average shortfalls of the household in Quintana Roo decreased, however, the income in 2016 remained in conditions similar to those of 2010 , that is, the reduction of extreme poverty can be attribute only to state intervention through the creation of infrastructure and not the effectiveness of its economic policies.

KEY WORDS: Poverty; Extreme Poverty; Social Policy; Poverty Measurement; Quintana Roo.

\section{INTRODUCCIÓN}

El sexenio 2012-2018 representó para México el regreso del Partido Revolucionario Institucional (PRI) al poder. Esto derivó en el mantenimiento de una serie de reformas neoliberales de lo más agresivas que la población mexicana haya visto desde finales de 1980 cuando Carlos Salinas de Gortari fue presidente. De ahí que el 2018 represente un año importantísimo en la coyuntura política y económica para México. Por ello es que surge la necesidad de saber en qué condiciones se encuentran las entidades federativas, especialmente en asuntos tan delicados y urgentes de solucionar como la pobreza. Durante las campañas electorales de 2018 en México, el candidato del PRI, Jose Meade, levantó polémica al asegurar que durante su gestión como secretario de desarrollo social había logrado sacar a 2 millones de mexicanos de la pobreza extrema. Ríos de tinta corrieron sobre la mencionada afirmación pues la cifra parece deslumbrar a primera vista, sin embargo, si se revisa con cuidado la metodología que el Consejo Nacional de Evaluación de la Política de Desarrollo Social (CONEVAL) implementa, la realidad es otra.

Ante este panorama se determinó analizar el comportamiento de la pobreza y sus indicadores en el caribeño estado de Quintana Roo en México para poder determinar si la pobreza disminuyó en términos reales o si la disminución está atribuida al diseño metodológico que el CONEVAL tiene para la medición de la pobreza en México. Para ello primero se hizo una extensa revisión sobre las metodologías implementadas en México para tipificar, medir e identificar la pobreza, así como las corrientes teórico-conceptuales que

\footnotetext{
"Visión de Futuro" Año 17, Volumen N² 24 Nº1, Enero - Junio 2020 - Pág. 193 - 215

URL de la Revista: http://visiondefuturo.fce.unam.edu.ar/index.php/visiondefuturo/index

URL del Documento: http://visiondefuturo.fce.unam.edu.ar/index.php/visiondefuturo/issue/view/17

ISSN 1668 - 8708 - Versión en Línea

E-mail: revistacientifica@fce.unam.edu.ar
} 
soportan trabajos similares. En la segunda sección se delimita la metodología que en su totalidad fue de gabinete, para finalmente exponer los resultados y las conclusiones.

\section{DESARROLLO}

En la literatura existen esfuerzos académicos importantes que han abonado a la discusión sobre la correcta medición de la pobreza. Los informes sobre pobreza del Banco Mundial de 1992 son pioneros sobre este tema, pues en ellos se estableció que el ingreso era la variable clave para poder conocer el grado de pobreza en los individuos, es decir, el enfoque era unidimensional. Esto, naturalmente, desató una oleada de posturas a favor y en contra sobre la metodología adoptada por Banco Mundial donde se estableció que tener ingresos inferiores a 1.25 dólares americanos era igual a ser pobre.

Entre los trabajos que surgieron como oposición intelectual a esa metodología se puede nombrar el de Sen $(1976,2000)$ quien planteaba que la pobreza debía ser abordada desde una perspectiva dual, es decir, desde el papel del Estado y en el hacer de los individuos, a esto él le llamó el enfoque de libertades y capacidades. Otro trabajo notable y que es referencia obligada es el de Alkire y Foster $(2007$, p. 2) quienes presentaron una serie de artículos para la Oxford Poverty \& Human Development Initiative en donde proponen

"un enfoque intuitivo que utiliza dos tipos de línea de corte para identificar a los pobres. La primera es la línea tradicional de pobreza o línea de corte basada en dimensiones específicas, que identifica si una persona sufre privaciones en relación con esa dimensión. La segunda, marca cuán amplias deben ser las privaciones que sufre una persona para ser considerada pobre".

Una metodología poco difundida pero que presenta una lógica y postura interesante es la que utiliza el Planning Institute of Jamaica. Esta nación caribeña estableció como metodología de medición de pobreza dos variantes: pobreza pública, que se refiere a la población que tiene tal carencia de ingreso que no puede ni siquiera acceder a los bienes y servicios ofrecidos por el Estado; y, pobreza privada, la cual se refiere a la imposibilidad de consumir en niveles reales las canastas alimentarias y no alimentarias (PIOJ, 2007).

Se pueden mencionar también otras metodologías para medición de pobreza en poblaciones específicas, por ejemplo, la UNICEF (2000) y Gordon et al. (2003), propusieron una metodología para medir la pobreza en niños a través de indicadores que ilustran el grado de carencias que esta población tiene, es decir, los resultados indicarán si un niño está en situación de no privación, privación leve, privación moderada, privación severa, o Privación extrema. Este enfoque se basa en el principio multidimensional para la medición de pobreza. Dicho enfoque es el mismo que la Comisión Económica para América Latina y el Caribe 
(CEPAL) utilizó para proponer el método de Necesidades Básicas Insatisfechas (NBI) y que es el utilizado en México.

En lo que refiere al caso mexicano, en la década de 1980 tras los terribles resultados en materia económica de los sexenios de Luis Echeverria (1970-1976) y José López Portillo (1976-1982) el gobierno federal emprendió una cruzada para comenzar a diseñar políticas de combate a la pobreza que ya se hacía presente de manera alarmante en las estadísticas nacionales. Sin embargo a ciencia cierta nadie se había encargado de medir o estimar el número de pobres que existían en México. Esta preocupación no era exclusivamente mexicana, pues toda Latinoamérica y el Caribe comenzaban a sentir los estragos del fin del modelo del Estado benefactor y el inicio del neoliberalismo. En ese sentido, a través de la Comisión Económica para América Latina y el Caribe (CEPAL) el fenómeno de la pobreza ya comenzaba a ser escrudiñado en la década de 1970 por Altmir (1979) quien en un vasto documento propone adoptar dos métodos para poder medir la pobreza: la Canasta Normativa Alimentaria (CNA) y la Línea de Pobreza (LP). En México los trabajos más importantes los llevó a cabo el gobierno federal a través de la Coordinación General del Plan Nacional de Zonas Deprimidas y Grupos Marginados (COPLAMAR). En una serie de publicaciones la COPLAMAR indagó sobre lo que consideró las categorías de análisis que explicaban la pobreza:

- Alimentación

- Requerimientos nutricionales del hogar

- Gasto en alimentos de la Canasta Normativa Alimentaria

- Educación
- Deserción escolar
- Población de 15 años y más sin primaria completa
- Asistencia escolar
- Alfabetismo

- Vivienda

- Protección

- Higiene

- Privacidad

- Comodidad

- Funcionalidad

- Localización

- Seguridad en la tenencia

- Salud

\footnotetext{
"Visión de Futuro" Año 17, Volumen N²4 N¹, Enero - Junio 2020 - Pág. 193 - 215

URL de la Revista: http://visiondefuturo.fce.unam.edu.ar/index.php/visiondefuturo/index

URL del Documento: http://visiondefuturo.fce.unam.edu.ar/index.php/visiondefuturo/issue/view/17 
- Acceso a agua potable y alcantarillado

- Atención universal de los servicios no personales de salud

- Extensión universal de los servicios no personales de salud

- Ingreso

o Líneas de pobreza (COPLAMAR, 1982, 1982a, 1982b, 1982c, 1982d, 1982e; Boltvinik, 1990).

Ese estudio estuvo estrechamente sustentado por la metodología de medición de la pobreza que la CEPAL comenzaba a poner en práctica en la década de 1980: El método de las Necesidades Básicas Insatisfechas (NBI).

Autores como Feres y Mancero (2001, p. 65) señalan que el método de NBI fue

"Introducido por la CEPAL (...) para aprovechar la información de los censos demográficos y de vivienda en la caracterización de la pobreza". Las necesidades que se consideraron como dimensiones fueron "i. Acceso a una vivienda que asegure un estándar mínimo de habitabilidad para el hogar; ii. Acceso a servicios básicos que aseguren un nivel sanitario adecuado; iii. Acceso a educación básica; iv. Capacidad económica para alcanzar niveles mínimos de consumo" (Feres y Mancero, 2001, p. 67).

Este último criterio de capacidad económica está inferido en metodologías como el de Líneas de pobreza, que según autores como Boltvinik (2012) representan métodos de tipo normativos pues incluyen una definición de normas (o umbrales).

Esta metodología de NBI se desagrega de la siguiente manera

- "Acceso a vivienda

- Calidad de la vivienda

- Materiales de construcción utilizados en piso, paredes y techo

- Hacinamiento

- Número de personas en el hogar

- Número de cuartos de la vivienda

- Acceso a servicios sanitarios

- Disponibilidad de agua potable

- Fuente de abastecimiento de agua en la vivienda

- Tipo de sistema de eliminación de excretas

- Disponibilidad de servicio sanitario

- Sistema de eliminación de excretas

- Acceso a educación

- Asistencia de los niños en edad escolar a un establecimiento educativo

- Edad de los miembros del hogar

- Asistencia a un establecimiento educativo

- Capacidad económica

- Probabilidad de insuficiencia de ingresos del hogar

- Edad de los miembros del hogar

- Último nivel educativo aprobado

- Número de personas en el hogar

- Condición de actividad" (Feres y Mancero, 2001, p. 67).

El uso de estos indicadores se volvió regular en México hasta 2004, cuando el presidente Vicente Fox promulgó la Ley de Desarrollo Social en la que se estableció en el artículo 1, fracción II como obligación del gobierno mexicano el "establecer las instituciones

\footnotetext{
“Visión de Futuro" Año 17, Volumen N²4 N¹, Enero - Junio 2020 - Pág. 193 - 215

URL de la Revista: http://visiondefuturo.fce.unam.edu.ar/index.php/visiondefuturo/index

URL del Documento: http://visiondefuturo.fce.unam.edu.ar/index.php/visiondefuturo/issue/view/17

ISSN 1668 - 8708 - Versión en Línea

E-mail: revistacientifica@fce.unam.edu.ar
} 
responsables del desarrollo social y definir los principios y lineamientos generales a los que debe sujetarse la Política Nacional de Desarrollo" (LGDS, 2004, p. 1). La fracción VIII de la mencionada ley afirma que se deben "Establecer mecanismos de evaluación y seguimiento de los programas y acciones de la Política Nacional de Desarrollo Social" (LGDS, 2004, p. 2). Asimismo, el Reglamento de la Ley de Desarrollo Social en su artículo 37 establece de manera puntual que "Las personas o grupos sociales en situación de pobreza serán aquellos que identifique la secretaría, con sujeción a los lineamientos y criterios que para la definición, identificación y medición de la pobreza establezca el Consejo Nacional de Evaluación" (RLGDS, 2004, p. 8). Así, estos criterios jurídicos dieron nacimiento al Consejo Nacional de evaluación de la Política de Desarrollo Social, organismo cuya responsabilidad es

emitir los lineamientos y criterios para la definición, identificación y medición de la pobreza con base en la información que genere el Instituto Nacional de Estadística y Geografía (INEGI) mediante los siguientes indicadores: ingreso corriente per cápita, rezago educativo, acceso a los servicios de salud, acceso a la seguridad social, calidad y espacios de la vivienda, acceso a los servicios básicos en la vivienda, acceso a la alimentación y grado de cohesión social (CONEVAL, 2016, p. 14).

Posterior a la creación del CONEVAL, casi seis años después, en el Diario Oficial de la Federación se publicaron los Lineamientos y criterios generales para la definición, identificación y medición de la pobreza. Este documento plantea y esboza todas las dimensiones, subdimensiones, categorías e items que la medición de la pobreza en México deberá tomar en cuenta. En el título segundo, del mencionado documento, De la definición de la pobreza se establece que

CUARTO.- La definición de pobreza considera las condiciones de vida de la población a partir de tres espacios: el del bienestar económico, el de los derechos sociales y el del contexto territorial. QUINTO.- El espacio del bienestar económico comprenderá las necesidades asociadas a los bienes y servicios que puede adquirir la población mediante el ingreso. SEXTO.- El espacio de los derechos sociales se integrará a partir de las carencias de la población en el ejercicio de sus derechos para el desarrollo social (...). SÉPTIMO.- El espacio de los derechos sociales se integrará a partir de las carencias de la población en el ejercicio de sus derechos para el desarrollo social (...) El espacio de los derechos sociales se integrará a partir de las carencias de la población en el ejercicio de sus derechos para el desarrollo social. OCTAVO.- La población en situación de pobreza multidimensional será aquella cuyos ingresos sean insuficientes para adquirir los bienes y los servicios que requiere para satisfacer sus necesidades y presente carencia en al menos uno de los siguientes seis indicadores: rezago educativo, acceso a los servicios de salud, acceso a la seguridad social, calidad y espacios de la vivienda, servicios básicos en la vivienda y acceso a la alimentación (DOF, 2010, p. 2).

El Capítulo II Del espacio del bienestar económico establece que:

"DÉCIMO PRIMERO.- La población en situación de pobreza multidimensional será aquella cuyos ingresos sean totalmente insuficientes para adquirir los bienes y los servicios que requiere para satisfacer sus necesidades y presente carencia en al menos uno de los siguientes seis indicadores: rezago educativo, acceso a los servicios de salud, acceso a la seguridad social, calidad y espacios de la vivienda, servicios básicos en la vivienda y acceso a la alimentación (DOF, 2010, p. 3),

\footnotetext{
"Visión de Futuro" Año 17, Volumen No 24 N¹, Enero - Junio 2020 - Pág. 193 - 215

URL de la Revista: http://visiondefuturo.fce.unam.edu.ar/index.php/visiondefuturo/index

URL del Documento: http://visiondefuturo.fce.unam.edu.ar/index.php/visiondefuturo/issue/view/17

ISSN 1668 - 8708 - Versión en Línea

E-mail: revistacientifica@fce.unam.edu.ar
} 
Además, es ese capítulo se establece que debe hacerse una distinción entre el ámbito rural y urbano en la utilización de las líneas de bienestar y bienestar mínimo.

En el capítulo III De las carencias sociales se establecen los criterios para cada carencia social a medir:

I.-En materia de rezago educativo: a) Población de 3 a 15 años que no cuenta con la educación secundaria terminada y no asiste a la escuela. b) Población nacida hasta 1981 que no cuenta con la educación primaria terminada. c) Población nacida a partir de 1982 que no cuenta con la educación secundaria terminada. II.- En materia de acceso a los servicios de salud: a) Población no afiliada o inscrita para recibir servicios de salud por parte del Seguro Popular, y que tampoco es derechohabiente de alguna institución de seguridad social. III.- En materia de acceso a la seguridad social: a) Población ocupada y asalariada que no recibe por parte de su trabajo las prestaciones de servicios médicos, incapacidad con goce de sueldo y SAR o Afore. b) Población ocupada y no asalariada que no recibe como prestación laboral (...). c) Población sin acceso a la seguridad social por alguno de los primeros dos criterios, que no goce de alguna jubilación o pensión, ni sea familiar directo de una persona dentro o fuera del hogar con acceso a la seguridad social. d) Población de 65 años o más que no dispone de acceso a la seguridad social por alguno de los criterios anteriores ni es beneficiario de algún programa social de pensiones para adultos mayores. IV.- En materia de calidad y espacios de la vivienda, la población que resida en viviendas con al menos una de las siguientes características: a) El material de la mayor parte de los pisos es tierra. b) El material de la mayor parte del techo es lámina de cartón o desechos. c) El material de la mayor parte de los muros es embarro o bajareque; carrizo, bambú o palma; lámina de cartón, metálica o de asbesto; o material de desecho. d) Con hacinamiento. V.- En materia de acceso a los servicios básicos en la vivienda, la población que resida en viviendas con al menos una de las siguientes características: a) El agua se obtiene de un pozo, río, lago, arroyo, pipa, o bien, el agua entubada la obtienen por acarreo de otra vivienda, o de la llave pública o hidrante. b) No disponen de drenaje, o el desagüe tiene conexión a una tubería que va a dar a un río, lago, mar, barranca o grieta. c) No disponen de energía eléctrica. VI.- En materia de acceso a la alimentación: a) Población en hogares con un grado de inseguridad alimentaria moderado o severo (DOF, 2010, p. 3-4).

Así, según los propios Lineamientos y Criterios generales para la definición, identificación y medición de la pobreza (DOF, 2010) la clasificación de pobreza obedece al número de carencias que posee un hogar en combinación con su situación de ingreso respecto a las líneas de bienestar y bienestar mínimo. Según el CONEVAL (2018) y el INEGI (2018) se considera a que una persona está en situación de pobreza o vulnerabilidad bajo los criterios que se perfilan en la tabla 1:

Tabla No1. Tipología de pobreza según los lineamien tos y criterios generales para la definición, identificación y medición de la pobreza del CONEVAL

\begin{tabular}{|c|c|c|c|c|}
\hline & Concepto & Definición & $\begin{array}{l}\text { Número de } \\
\text { carencias } \\
\text { requeridas }\end{array}$ & $\begin{array}{ll}\text { Criterio de } & \text { línea de } \\
\text { bienestar }\end{array}$ \\
\hline \multirow[t]{2}{*}{$\begin{array}{l}\text { POBREZA } \\
\text { MULTI- } \\
\text { DIMENSIONAL }\end{array}$} & Pobreza & $\begin{array}{l}\text { Una persona se encuentra en situación de } \\
\text { pobreza cuando tiene al menos una } \\
\text { carencia y su ingreso es insuficiente para } \\
\text { adquirir los bienes y servicios que requiere } \\
\text { para satisfacer sus necesidades } \\
\text { alimentarias y no alimentarias. }\end{array}$ & Una & $\begin{array}{l}\text { Ingreso por } \\
\text { debajo de la } \\
\text { Línea de } \\
\text { Bienestar } \\
\text { Mínimo }\end{array}$ \\
\hline & $\begin{array}{l}\text { Pobreza } \\
\text { extrema }\end{array}$ & $\begin{array}{l}\text { Una persona se encuentra en situación de } \\
\text { pobreza extrema cuando tiene tres o más }\end{array}$ & Tres o más & $\begin{array}{l}\text { Ingreso por } \\
\text { debajo de la }\end{array}$ \\
\hline
\end{tabular}

\footnotetext{
“Visión de Futuro" Año 17, Volumen N²4 N¹, Enero - Junio 2020 - Pág. 193 - 215

URL de la Revista: http://visiondefuturo.fce.unam.edu.ar/index.php/visiondefuturo/index

URL del Documento: http://visiondefuturo.fce.unam.edu.ar/index.php/visiondefuturo/issue/view/17

ISSN 1668 - 8708 - Versión en Línea

E-mail: revistacientifica@fce.unam.edu.ar
} 


\begin{tabular}{|c|c|c|c|c|}
\hline & & $\begin{array}{l}\text { carencias, de seis posibles, dentro del } \\
\text { Índice de Privación Social y que, además, } \\
\text { se encuentra por debajo de la línea de } \\
\text { bienestar mínimo. Las personas en esta } \\
\text { situación disponen de un ingreso tan bajo } \\
\text { que, aun si lo dedicase por completo a la } \\
\text { adquisición de alimentos, no podría adquirir } \\
\text { los nutrientes necesarios para tener una } \\
\text { vida sana. }\end{array}$ & & $\begin{array}{l}\text { Línea de } \\
\text { Bienestar } \\
\text { Mínimo }\end{array}$ \\
\hline & $\begin{array}{l}\text { Vulnerable } \\
\text { por carencia } \\
\text { social }\end{array}$ & $\begin{array}{l}\text { Aquella población que presenta una o más } \\
\text { carencias sociales, pero cuyo ingreso es } \\
\text { superior a la línea de bienestar. }\end{array}$ & Una o más & $\begin{array}{l}\text { Ingreso por } \\
\text { encima de } \\
\text { la Línea de } \\
\text { Bienestar } \\
\text { Mínimo }\end{array}$ \\
\hline & $\begin{array}{l}\text { Vulnerable } \\
\text { por ingresos }\end{array}$ & $\begin{array}{l}\text { Aquella población que no presenta } \\
\text { carencias sociales pero cuyo ingreso es } \\
\text { inferior o igual a la línea de bienestar. }\end{array}$ & Ninguna & $\begin{array}{l}\text { Ingreso } \\
\text { igual o por } \\
\text { debajo de la } \\
\text { Línea de } \\
\text { Bienestar }\end{array}$ \\
\hline & $\begin{array}{l}\text { No pobres y } \\
\text { no } \\
\text { vulnerables }\end{array}$ & $\begin{array}{l}\text { Aquella población cuyo ingreso es superior } \\
\text { a la línea de bienestar y que no tiene } \\
\text { ninguna de las carencias sociales que se } \\
\text { utilizan en la medición de la pobreza. }\end{array}$ & Ninguna & $\begin{array}{l}\text { Ingreso por } \\
\text { encima de } \\
\text { la Línea de } \\
\text { Bienestar }\end{array}$ \\
\hline \multirow[t]{3}{*}{$\begin{array}{l}\text { POBREZA POR } \\
\text { INGRESOS }\end{array}$} & $\begin{array}{l}\text { Pobreza } \\
\text { alimentaria }\end{array}$ & $\begin{array}{l}\text { Incapacidad para obtener una canasta } \\
\text { básica alimentaria, aun si se hiciera uso de } \\
\text { todo el ingreso disponible en el hogar para } \\
\text { comprar sólo los bienes de dicha canasta. }\end{array}$ & & \\
\hline & $\begin{array}{l}\text { Pobreza de } \\
\text { capacidades }\end{array}$ & $\begin{array}{l}\text { Insuficiencia del ingreso disponible para } \\
\text { adquirir el valor de la canasta alimentaria y } \\
\text { efectuar los gastos necesarios en salud y } \\
\text { educación, aun dedicando el ingreso total } \\
\text { de los hogares nada más que para estos } \\
\text { fines. }\end{array}$ & & \\
\hline & $\begin{array}{l}\text { Pobreza de } \\
\text { capacidades }\end{array}$ & $\begin{array}{l}\text { Insuficiencia del ingreso disponible para } \\
\text { adquirir la canasta alimentaria, así como } \\
\text { realizar los gastos necesarios en salud, } \\
\text { vestido, vivienda, transporte y educación, } \\
\text { aunque la totalidad del ingreso del hogar } \\
\text { fuera utilizado exclusivamente para la } \\
\text { adquisición de estos bienes y servicios. }\end{array}$ & & \\
\hline
\end{tabular}

Fuente: CONEVAL (2018: s/p); INEGI (2018: s/p)

En la literatura académica existen importantes trabajos empíricos que abordan la evaluación del comportamiento de la pobreza en México. Por ejemplo Aguilar, Caamal y Portillo (2018) hacen un interesante desagregado de pobreza multidimensional en México. Para su trabajo muestrearon a los municipios que tienen hogares con ingresos por debajo de la línea de bienestar, y los clasificaron por conglomerados para poder esbozarlos en mapas y que a partir de ello se puedan regionalizar los focos de pobreza a nivel nacional para así diseñar y aplicar políticas sociales diferenciadas. Otro trabajo destacado en el rubro es el de González y Barragán (2018) quienes analizan las condiciones de pobreza que existen en los municipios fronterizos norteños de México haciendo énfasis en el comportamiento de las condiciones de los barrios urbanos que se encuestaron en las bases de datos que usaron para su trabajo. Entre los resultados más importantes de este artículo están que si bien los municipios fronterizos tienen un comportamiento aceptable en materia de pobreza moderada,

\footnotetext{
"Visión de Futuro" Año 17, Volumen No 24 N¹, Enero - Junio 2020 - Pág. 193 - 215

URL de la Revista: http://visiondefuturo.fce.unam.edu.ar/index.php/visiondefuturo/index

URL del Documento: http://visiondefuturo.fce.unam.edu.ar/index.php/visiondefuturo/issue/view/17

ISSN 1668 - 8708 - Versión en Línea

E-mail: revistacientifica@fce.unam.edu.ar
} 
de capacidades y patrimonial dada su cercanía y relación con condados de Estados Unidos, esta estabilidad se podría ver afectada por la recesión norteamericana que se manifestó a partir del año 2000 y que, ante el arribo de nuevos migrantes podría generar un efecto de burbuja en la cantidad de pobres extremos que hay en la región de estudio.

El trabajo de Herrera y Castro (2018) resulta muy valioso y de interés académico, pues estos autores proponen un modelo de encuesta y de regresión logística para medir pobreza en San Andrés Cholula, Puebla, que combina metodologías del Consejo Nacional de Población, del INEGI y de la teoría de la psicología positiva. Entre los resultados más importantes está por un lado que el ingreso es un factor con un alto peso en el modelo de regresión, y por otro lado, que en esa localidad el gasto en educación es alto, lo que impide que los hogares puedan destinar gasto a otros menesteres o ahorrar. En Campos y Rodas (2019), los autores proponen que se debe cambiar la política fiscal y económica para poder combatir de manera real el problema de la desigualdad en términos del ingreso, es decir, mejorar la tributación, especialmente para los hogares con ingresos altos; y, gasto focalizado y coordinado para reducir la desigualdad y mejorar la promoción de la movilidad social.

Canto (2019) aborda la pobreza y la desigualdad en México desde el ingreso. En su trabajo, el autor plantea que gran parte del problema con la pobreza tiene que ver con la precariedad salarial y la incapacidad que algunos hogares tienen para adquirir la canasta básica. En este trabajo se aboga por la reorientación de las políticas sociales hacia "la redistribución de la riqueza y el poder para detener la creciente polarización social que afecta la estabilidad social y política del país" (Canto, 2019, p. 1204). Otro interesante estudio es el de Torres y Rojas (2015) quienes presentan un completo análisis sobre los pobres resultados de la política económica y social en México a partir de la implementación del modelo neoliberal o de economía abierta, como ellos le llaman, pues con los continuos recortes del gasto público, hay evidencia del abandono de la gestión y promoción del desarrollo por parte del Estado, y lo más interesante es el cómo los autores concluyen que mientras la política social siga siendo usada como un mecanismo compensador de las consecuencias de la política económica, jamás habrá modo de mejorar las condiciones de vida de la población en situación de pobreza.

Barajas (2018) hace una intensa revisión sobre las condiciones históricas y de presupuesto en la política de combate a la pobreza en México por parte de la Secretaría de Desarrollo Social, y señala que en México la política social es más orientada a la cuestión política y electoral que a la solución de la pobreza, o como la propia autora lo plantea, la política social "no está vinculada con la reducción de la pobreza en el país, sino con la necesidad de darle viabilidad a un modelo económico que genera pobres (los programas atienden a las personas que se quedan al margen del desarrollo), y legitimar al gobierno que 
promueve tal modelo" (Barajas, 2018, p. 1). Mientras que en lo que refiere a estudios sobre pobreza en estados de México o a nivel regional se pueden destacar los trabajos de Székely et al. (2007) quienes elaboraron un importante reporte cartográfico sobre pobreza según sus tipologías para todos los estados y municipios en México. La lógica del estudio propuesto por estos autores se basa en el supuesto de que existe sesgo estadístico entre los resultados de los censos y de las ENIGH que el INEGI genera. Por ello es que presentan una metodología que

\footnotetext{
"estima un modelo de ingresos y un modelo de heteroscedasticidad a partir de los datos de una encuesta de hogares. En la segunda etapa se "imputa" un ingreso a cada uno de los hogares del Censo utilizando el vector de parámetros obtenido en la primera etapa y se incorpora el modelo de heteroscedasticidad para minimizar los errores en el cálculo del ingreso" (Székely et al. 2007, p. 241).
}

y concluyen que según sus cálculos, la mayor concentración de pobreza y desigualdad se localiza en el sur del país, mientras que las menor cantidad de población pobre y en condiciones de desigualdad está en la frontera norte.

Es importante señalar que en la literatura especializada existe un hueco muy significativo en lo que a medición de la pobreza, específicamente en el estado de Quintana Roo, refiere. En una revisión electrónica se encontraron unos pocos artículos que tocan de manera tangencial el fenómeno de la pobreza en territorio quintanarroense, o bien lo hacen de manera parcial. Por ejemplo Toscana y Reyes (2018) plantean un análisis de ruralidad en la Zona Maya en función de los ingresos y la estructura económica que tienen los hogares muestra. Entre los principales resultados de este trabajo destaca que los autores proponen una nueva categoría de análisis para la población de zonas rurales que no son campesinos, ni proletarios agrícolas, sino dependientes de transferencias monetarias condicionadas. Los trabajos de Barrera y Reyes (2013), Reyes y Barrera (2014) y Barrera (2018) abordan la pobreza y el efecto que tienen las transferencias monetarias condicionadas (TMC) en el ingreso en hogares de la etnia Maya principalmente en los municipios de Felipe Carrillo Puerto y José María Morelos, y aunque los resultados que arrojan son interesantes y pioneros pues ponen en evidencia una latente dependencia de los hogares de estudio hacia las TMC, tienen sesgo geográfico pues dejan de lado al resto de los municipios de Quintana Roo.

\section{Método}

Para poder dar cumplimiento al objetivo planteado se realizó trabajo de gabinete en dos partes. Primero, se descargaron las bases de datos de CONEVAL sobre evaluación de la pobreza por estado y municipio 2010-2015. De ello, se filtró la información solo del estado de

\footnotetext{
"Visión de Futuro" Año 17, Volumen N² 24 Nº1, Enero - Junio 2020 - Pág. 193 - 215

URL de la Revista: http://visiondefuturo.fce.unam.edu.ar/index.php/visiondefuturo/index

URL del Documento: http://visiondefuturo.fce.unam.edu.ar/index.php/visiondefuturo/issue/view/17

ISSN 1668 - 8708 - Versión en Línea

E-mail: revistacientifica@fce.unam.edu.ar
} 
Quintana Roo y sus municipios ${ }^{1}$ para así analizar los datos sobre pobreza, pobreza extrema, vulnerables por carencias, vulnerables por ingreso, y todas las carencias que el CONEVAL tipifica. Esto permitió dar cuenta de la situación de pobreza en el ámbito de dimensiones.

Para analizar la cuestión de bienestar económico o ingreso descargaron los módulos de condiciones sociales de la ENIGH 2012, 2014 y 2016 (INEGI, 2013, 2015, 2017) para poder analizar la variable Ingreso Corriente (IC). Dicha variable se descompone en 1. Ingreso del Trabajo; 2. Renta de la Propiedad; 3. Transferencias; 4. Estimación del Alquiler de la vivienda; y 5. Otros Ingresos Corrientes (INEGI, 2015). El IC habrá de servir como medio de contraste para saber si el comportamiento de la pobreza en cualquiera de sus variantes está explicada por las dimensiones que la conforman o bien por cómo se movió el IC.

Es importante señalar que, pese a las constantes críticas sobre el sesgo estadístico y geográfico (Székely et al. 2007; Damian, 2007) a nivel micro que la ENIGH tiene, es esta encuesta la única fuente de información a nivel nacional que se genera en México de manera continua, pues anteriormente, casi toda la información se obtenía de los censos cada década. Ahora bien, la ENIGH, según el propio INEGI (2014, s/p)

"se caracteriza por ser probabilística; en consecuencia, los resultados obtenidos de la encuesta se generalizan a toda la población. A la vez tiene un diseño bietápico, estratificado y por conglomerados, donde la unidad última de selección es la vivienda y la unidad de observación es el hogar".

Sin esta encuesta, la información referente a las percepciones y gastos de los hogares se reduciría a bases de datos producto de esfuerzos académicos individuales y sumamente focalizadas que derivarían en información heterogénea y con aún más sesgo del que se critica que actualmente tiene. Así, la base de datos que se trabajó para este documento y que aborda al total del estado de Quintana Roo (Mapa 1) se compuso de la siguiente manera:

- ENIGH $2016 \rightarrow 1,728$ hogares en total (2.4\% de la muestra nacional)

○ 87 en Cozumel, 61 en Felipe Carrillo Puerto, 6 en Isla Mujeres, 414 en Othón P. Blanco, 792 en Benito Juárez, 61 en José María Morelos, 22 en Lázaro Cárdenas, 216 en Solidaridad, 69 en Tulum.

- ENIGH 2014 $\rightarrow 517$ hogares en total (2.4\% de la muestra nacional)

- 36 en Cozumel, 18 en Felipe Carrillo Puerto, 16 en Isla Mujeres, 93 en Othón P. Blanco, 239 en Benito Juárez, 20 en José María Morelos, 57 en Solidaridad, 28 en Tulum

- ENIGH $2012 \rightarrow 277$ hogares en total (2.7\% de la muestra nacional)

$1 \quad$ Las claves de lectura de las tablas y gráficas son las siguientes: CZ-Cozumel; FCP-Felipe Carrillo Puerto; IM-Isla Mujeres; OPB-Othón P. Blanco; BJ-Benito Juárez; JMM-José María Morelos; LC-Lázaro Cárdenas; Sol-Solidaridad; Tul-Tulúm; Bac-Bacalar. 


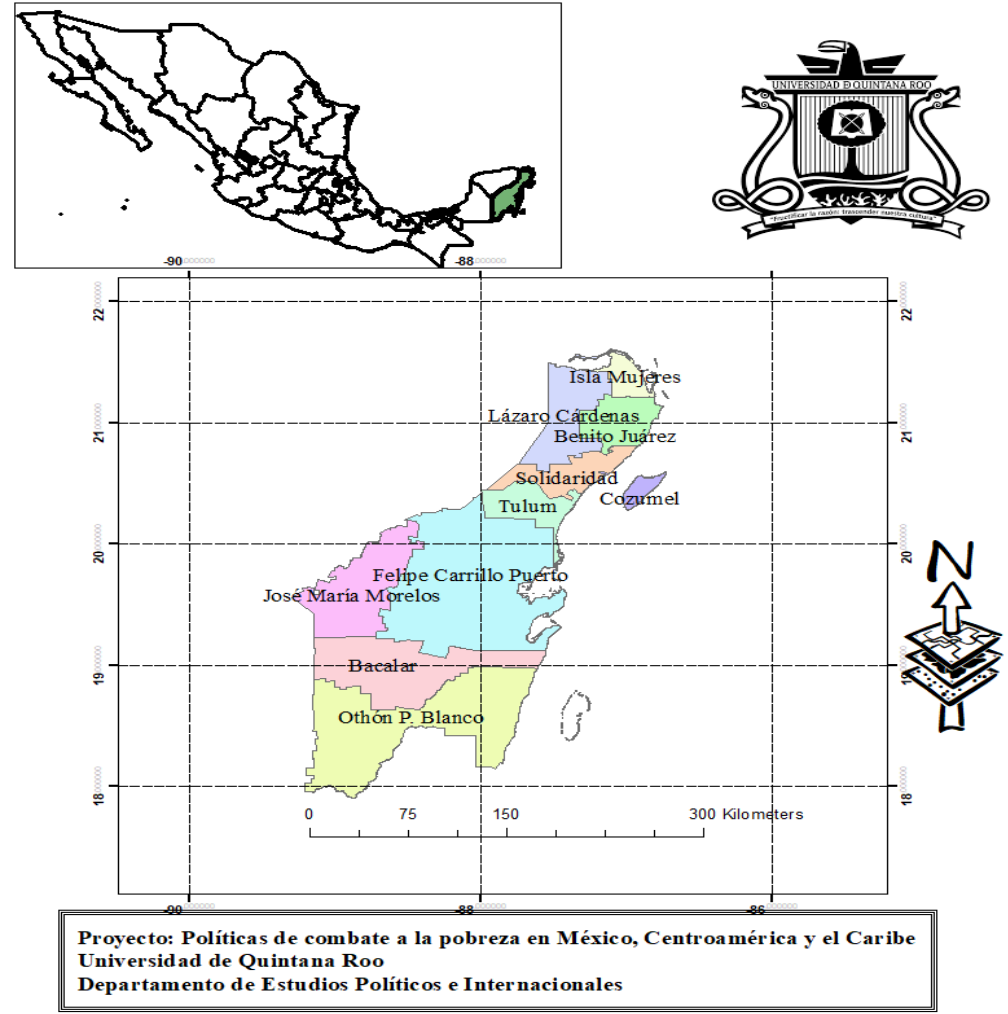

Fuente: Elaboración propia en Arc Map

\section{Resultados}

Como se observa en la tabla 2 y 3 la disminución de la cantidad de personas en todos los tipos de pobreza en los municipios de Quintana Roo es muy baja, 14 de 45 datos tuvieron tasas negativas de crecimiento. De hecho el resultado más notable es el de Tulum en lo que a Vulnerables por ingreso respecta con $-37.2 \%$ y Othón P. Blanco en Pobreza extrema con $35.7 \%$, por el contrario resulta alarmante el aumento de vulnerables por ingreso de José María Morelos, Felipe Carrillo Puerto (municipios con una altísima concentración de población perteneciente a la étnia Maya) y Cozumel con 107.4\%, 76.3 y $71.4 \%$.

Tabla N2. Matriz de pobreza para municipios de Qui ntana Roo (2010-2015)

\begin{tabular}{|c|c|c|c|c|c|c|c|c|c|c|c|c|}
\hline & \multicolumn{2}{|c|}{ Pobreza } & \multicolumn{2}{|c|}{$\begin{array}{l}\text { Pobreza } \\
\text { extrema }\end{array}$} & \multicolumn{2}{|c|}{$\begin{array}{l}\text { Pobreza } \\
\text { moderada }\end{array}$} & \multicolumn{2}{|c|}{$\begin{array}{l}\text { Vulnerables por } \\
\text { carencia }\end{array}$} & \multicolumn{2}{|c|}{$\begin{array}{l}\text { Vulnerables } \\
\text { por ingreso }\end{array}$} & \multicolumn{2}{|c|}{$\begin{array}{ll}\text { No pobres no } \\
\text { vulnerables }\end{array}$} \\
\hline & 2010 & 2015 & 2010 & 2015 & 2010 & 2015 & 2010 & 2015 & 2010 & 2015 & 2010 & 2015 \\
\hline Cozumel & 25,517 & 27,470 & 2,808 & 2,662 & 22,710 & 24,808 & 29,684 & 29,349 & 5,403 & 9,261 & 22,830 & 21,820 \\
\hline $\begin{array}{l}\text { Felipe } \\
\text { Carrillo } \\
\text { Puerto }\end{array}$ & 47,135 & 57,630 & 15,624 & 19,842 & 31,511 & 37,788 & 19,217 & 15,357 & 1,277 & 2,252 & 4,694 & 4,970 \\
\hline $\begin{array}{l}\text { Isla } \\
\text { Mujeres }\end{array}$ & 8,834 & 8,199 & 969 & 797 & 7,864 & |7,402 & 7,733 & 11,523 & 584 & 787 & 1,586 & 2,656 \\
\hline
\end{tabular}

"Visión de Futuro" Año 17, Volumen N²4 N¹, Enero - Junio 2020 - Pág. 193 - 215

URL de la Revista: http://visiondefuturo.fce.unam.edu.ar/index.php/visiondefuturo/index

URL del Documento: http://visiondefuturo.fce.unam.edu.ar/index.php/visiondefuturo/issue/view/17

ISSN 1668 - 8708 - Versión en Línea

E-mail: revistacientifica@fce.unam.edu.ar 


\begin{tabular}{|l|l|l|l|l|l|l|l|l|l|l|l|l|}
\hline $\begin{array}{l}\text { Othón P. P. } \\
\text { Blanco }\end{array}$ & 115,835 & 90,498 & 21,338 & 13,720 & 94,497 & 76,778 & 75,651 & 78,489 & 13,872 & 14,315 & 59,457 & 59,220 \\
\hline $\begin{array}{l}\text { Benito } \\
\text { Juárez }\end{array}$ & 180,048 & 219,949 & 24,493 & 20,775 & 155,556 & 199,173 & 258,291 & 284,301 & 35,870 & 56,553 & 196,418 & 233,361 \\
\hline $\begin{array}{l}\text { José María } \\
\text { Morelos }\end{array}$ & 21,055 & 26,884 & 9,074 & 9,176 & 11,980 & 17,708 & 6,159 & 4,733 & 378 & 784 & 1,696 & 1,424 \\
\hline $\begin{array}{l}\text { Lázaro } \\
\text { Cárdenas }\end{array}$ & 20,190 & 20,261 & 4,848 & 5,484 & 15,342 & 14,777 & 10,997 & 11,234 & 144 & 164 & 707 & 1,166 \\
\hline Solidaridad & 40,398 & 43,810 & 5,658 & 4,112 & 34,740 & 39,698 & 71,358 & 111,502 & 6,439 & 6,949 & 44,796 & 61,822 \\
\hline Tulum & 12,709 & 12,366 & 2,728 & 2,051 & 9,981 & 10,315 & 12,395 & 22,347 & 586 & 368 & 2,359 & 3,308 \\
\hline Bacalar & & 23,585 & & 10,652 & & 12,933 & & 3,892 & & 760 & & 1,927 \\
\hline
\end{tabular}

Fuente: Elaboración con datos de CONEVAL (2018)

Tabla N3. Tasa de crecimiento 2010-2015 por tipolo gía de pobreza para municipios de Quintana Roo

\begin{tabular}{|c|c|c|c|c|c|c|}
\hline Municipio & pobreza & $\begin{array}{l}\text { pobreza } \\
\text { extrema }\end{array}$ & $\begin{array}{l}\text { pobreza } \\
\text { moderada }\end{array}$ & $\begin{array}{l}\text { vulnerables por } \\
\text { carencia }\end{array}$ & $\begin{array}{l}\text { vulnerables por } \\
\text { ingreso }\end{array}$ & $\begin{array}{l}\text { no pobres no } \\
\text { vulnerables }\end{array}$ \\
\hline Cz & 7.653721049 & -5.199430199 & 9.238221048 & -1.128554103 & 71.40477512 & -4.424003504 \\
\hline FCP & 22.26583218 & 26.9969278 & 19.92002793 & -20.08638185 & 76.35082224 & 5.879846613 \\
\hline IM & -7.188136744 & -17.750258 & -5.874872838 & 49.01073322 & 34.76027397 & 67.46532156 \\
\hline OPB & -21.87335434 & -35.70156528 & -18.75085982 & 3.751437522 & 3.193483276 & -0.398607397 \\
\hline BJ & 22.16131254 & -15.1798473 & 28.03941989 & 10.07003728 & 57.66099805 & 18.80835769 \\
\hline JMM & 27.68463548 & 1.124090809 & 47.8130217 & -23.15310927 & 107.4074074 & -16.03773585 \\
\hline LC & 0.351659237 & 13.11881188 & -3.682701082 & 2.155133218 & 13.88888889 & 64.92220651 \\
\hline Sol & 8.445962671 & -27.32414281 & 14.27173287 & 56.2571821 & 7.920484547 & 38.00785784 \\
\hline Tul & -2.698874813 & -24.81671554 & 3.34635808 & 80.29043969 & -37.20136519 & 40.22891056 \\
\hline Bac & & & & & & \\
\hline
\end{tabular}

Fuente: Elaboración con datos de CONEVAL (2018)

Para poder entender si la disminución de los indicadores de pobreza y pobreza extrema, así como de la moderada y los vulnerables por carencia social es necesario examinar la tabla 4 que contiene el comportamiento del número de carencias promedio por tipo de pobreza. Ahí se observa que en el rubro de pobreza solo Isla Mujeres no tuvo disminución de carencias y Lázaro Cárdenas permaneció igual. En lo que refiere a pobreza extrema Isla Mujeres y Othón P. Blanco permanecieron sin cambios, Mientras que Solidaridad fue el único que aumentó sus carencias. En el rubro de pobreza moderada Isla Mujeres aumentó sus carencias, mientras que el resto permaneció igual o con disminuciones. En la categoría Vulnerables por carencia social, solo Isla Mujeres y Lázaro Cárdenas registraron aumento de carencias.

Tabla N4. Carencias promedio 2010-2015 por tipo de pobreza

o vulnerabilidad en municipios de Quintana Roo

\begin{tabular}{|c|c|c|c|c|c|c|c|c|c|c|c|}
\hline \multirow[b]{2}{*}{$\begin{array}{l}\text { Municipi } \\
\circ\end{array}$} & \multicolumn{3}{|l|}{ Pobreza } & \multicolumn{3}{|c|}{ Pobreza extrema } & \multicolumn{3}{|c|}{ Pobreza moderada } & \multicolumn{2}{|c|}{$\begin{array}{l}\text { Vulnerables por } \\
\text { carencia social }\end{array}$} \\
\hline & $\begin{array}{l}\text { Carencia } \\
\text { s } \\
\text { promedio } \\
2010\end{array}$ & $\begin{array}{l}\text { Carencia } \\
\text { s } \\
\text { promedio } \\
2015\end{array}$ & $\begin{array}{l}\text { Diferenci } \\
\text { a }\end{array}$ & $\begin{array}{l}\text { Carencia } \\
\text { s } \\
\text { promedio } \\
2010\end{array}$ & $\begin{array}{l}\text { Carencia } \\
\text { s } \\
\text { promedio } \\
2015\end{array}$ & $\begin{array}{l}\text { Diferenci } \\
\text { a }\end{array}$ & $\begin{array}{l}\text { Carencia } \\
\text { s } \\
\text { promedio } \\
2010\end{array}$ & $\begin{array}{l}\text { Carencia } \\
\text { s } \\
\text { promedio } \\
2015\end{array}$ & $\begin{array}{l}\text { Diferenci } \\
\text { a }\end{array}$ & $\begin{array}{l}\text { Carencia } \\
\text { s } \\
\text { promedio } \\
2010\end{array}$ & $\begin{array}{l}\text { Carencia } \\
\text { s } \\
\text { promedio } \\
2015\end{array}$ \\
\hline Coz & 2.2 & 1.9 & -0.2 & 3.6 & 3.4 & -0.2 & 2.0 & 1.8 & -0.2 & 1.8 & 1.6 \\
\hline FCP & 2.8 & 2.7 & -0.1 & 3.6 & 3.4 & -0.2 & 2.3 & 2.3 & 0.0 & 2.2 & 2.1 \\
\hline IM & 2.0 & 2.3 & 0.3 & 3.6 & 3.6 & 0.0 & 1.8 & 2.2 & 0.4 & 1.8 & 1.9 \\
\hline
\end{tabular}

\footnotetext{
"Visión de Futuro" Año 17, Volumen No 24 N¹, Enero - Junio 2020 - Pág. 193 - 215

URL de la Revista: http://visiondefuturo.fce.unam.edu.ar/index.php/visiondefuturo/index

URL del Documento: http://visiondefuturo.fce.unam.edu.ar/index.php/visiondefuturo/issue/view/17

ISSN 1668 - 8708 - Versión en Línea

E-mail: revistacientifica@fce.unam.edu.ar
} 


\begin{tabular}{|l|l|l|l|l|l|l|l|l|l|l|l|}
\hline OPB & 2.4 & 2.2 & -0.1 & 3.6 & 3.5 & $\mathbf{0 . 0}$ & 2.1 & 2.0 & $-\mathbf{0 . 1}$ & 1.9 & $\mathbf{1 . 7}$ \\
BJ & 2.4 & 2.2 & -0.3 & 3.7 & 3.6 & -0.2 & 2.2 & 2.0 & $-\mathbf{0 . 2}$ & 1.9 & $\mathbf{1 . 7}$ \\
\hline JMM & 2.9 & 2.6 & $-\mathbf{0 . 3}$ & 3.6 & 3.4 & -0.2 & 2.4 & 2.2 & $-\mathbf{0 . 3}$ & 2.4 & $\mathbf{2 . 1}$ \\
\hline $\begin{array}{l}\text { LC } \\
\text { Sol }\end{array}$ & 2.7 & 2.7 & $\mathbf{0 . 0}$ & 3.6 & 3.5 & -0.1 & 2.4 & 2.5 & $\mathbf{0 . 0}$ & 2.2 & $\mathbf{2 . 3}$ \\
\hline $\begin{array}{l}\text { Tul } \\
\text { Bac }\end{array}$ & 2.4 & 2.4 & $-\mathbf{0 . 1}$ & 3.6 & 3.7 & $\mathbf{0 . 1}$ & 2.2 & 2.2 & $\mathbf{0 . 0}$ & 2.0 & $\mathbf{1 . 8}$ \\
\hline
\end{tabular}

Fuente: Elaboración con datos de CONEVAL (2018)

La gráfica 1 muestra la tasa de crecimiento por municipio de cada clasificación de pobreza. Llama la atención que en efecto, como han mencionado las autoridades federales, las tasas de crecimiento de pobreza extrema son negativas para casi todos los municipios, excepto Felipe Carrillo Puerto. Además de eso las tasas de crecimiento para pobreza son también negativas o muy bajas considerando que si las tasas de pobreza extrema disminuyeron, sea natural que las de pobreza aumenten dada la movilidad entre clasificaciones. En esta misma gráfica llama la atención el comportamiento que tuvo la tasa de crecimiento de la población vulnerable por ingreso, es decir, aquellos que no tienen carencias pero que su ingreso es bajo. En ese caso sólo Tulum registra tasas negativas, mientras que Solidaridad y Lázaro Cárdenas tienen tasas positivas bajas, sin embargo, dos municipios con una altísima actividad turística no solo nacional sino internacional, Benito Juárez y Cozumel, registran tasas positivas de $51 \%$ y $71 \%$ respectivamente. Esto pone en tela de juicio las bondades del modelo de generación de empleo y riqueza a través del turismo, pues, si bien las carencias en ambos municipios disminuyeron, los ingresos no están siendo suficientes para la población.

Gráfica N1. Tasa de crecimiento por clasificación de pobreza en Quintana Roo (2010-2015)

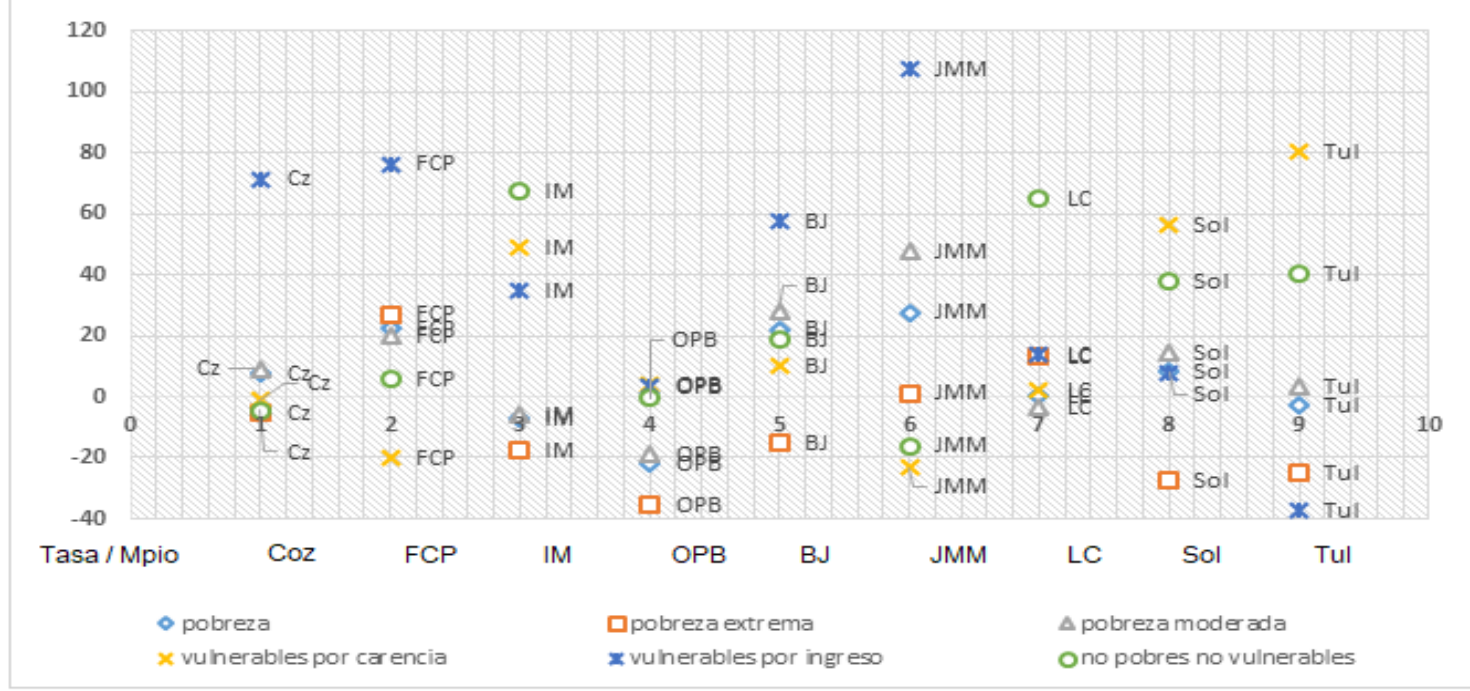

Fuente: Elaboración con datos de CONEVAL (2018)

\footnotetext{
"Visión de Futuro" Año 17, Volumen N²4 N¹, Enero - Junio 2020 - Pág. 193 - 215

URL de la Revista: http://visiondefuturo.fce.unam.edu.ar/index.php/visiondefuturo/index

URL del Documento: http://visiondefuturo.fce.unam.edu.ar/index.php/visiondefuturo/issue/view/17

ISSN 1668 - 8708 - Versión en Línea

E-mail: revistacientifica@fce.unam.edu.ar
} 
Ahora bien, en la gráfica 2 se clarifica bastante lo que la gráfica 1 devela, pues, se aprecia a mayor detalle las carencias que padecen todos los municipios en Quintana Roo. El dato más llamativo es el aumento del $650 \%$ de carencia por servicios de vivienda en el municipio de Solidaridad, el cual puede ser explicado por el boom demográfico que Playa del Carmen ha tenido como corazón de la Riviera Maya. Esto ha provocado migración masiva hacia este punto que, como evidencia la gráfica, no tenía infraestructura suficiente de vivienda con servicios básicos, de ahí la aparición de colonias irregulares en esta localidad (Camacho, 2015; Castillo y Méndez, 2017). Otro dato llamativo es que por un lado, las tasas de crecimiento de carencia por servicios básicos de la vivienda rondaron cerca del $100 \%$ en el caso de Tulum (120\%), Lázaro Cárdenas (98.2\%) y Felipe Carrillo Puerto (82.4\%). Por otro lado la carencia alimentaria tuvo tasas de crecimiento altas en Isla Mujeres (136.7\%) y Benito Juárez (56.7\%). Es de notar que los municipios más rurales no presenten tasas elevadas en carencia alimentaria, cuando sí presentaron tasas de crecimiento altas en vulnerabilidad por ingreso. Esto puede ser explicado por la agricultura y ganadería de traspatio, especialmente en localidades indígenas. El resto de las carencias tuvieron tasas de crecimiento normales e incluso negativas, por ejemplo Othón P. Blanco en servicios de salud registró $-45.2 \%$ y en vivienda $-39.2 \%$.

\section{Gráfica N2. Tasa de crecimiento de carencias y vul nerabilidad por ingreso en Quintana Roo (2010-2015)}

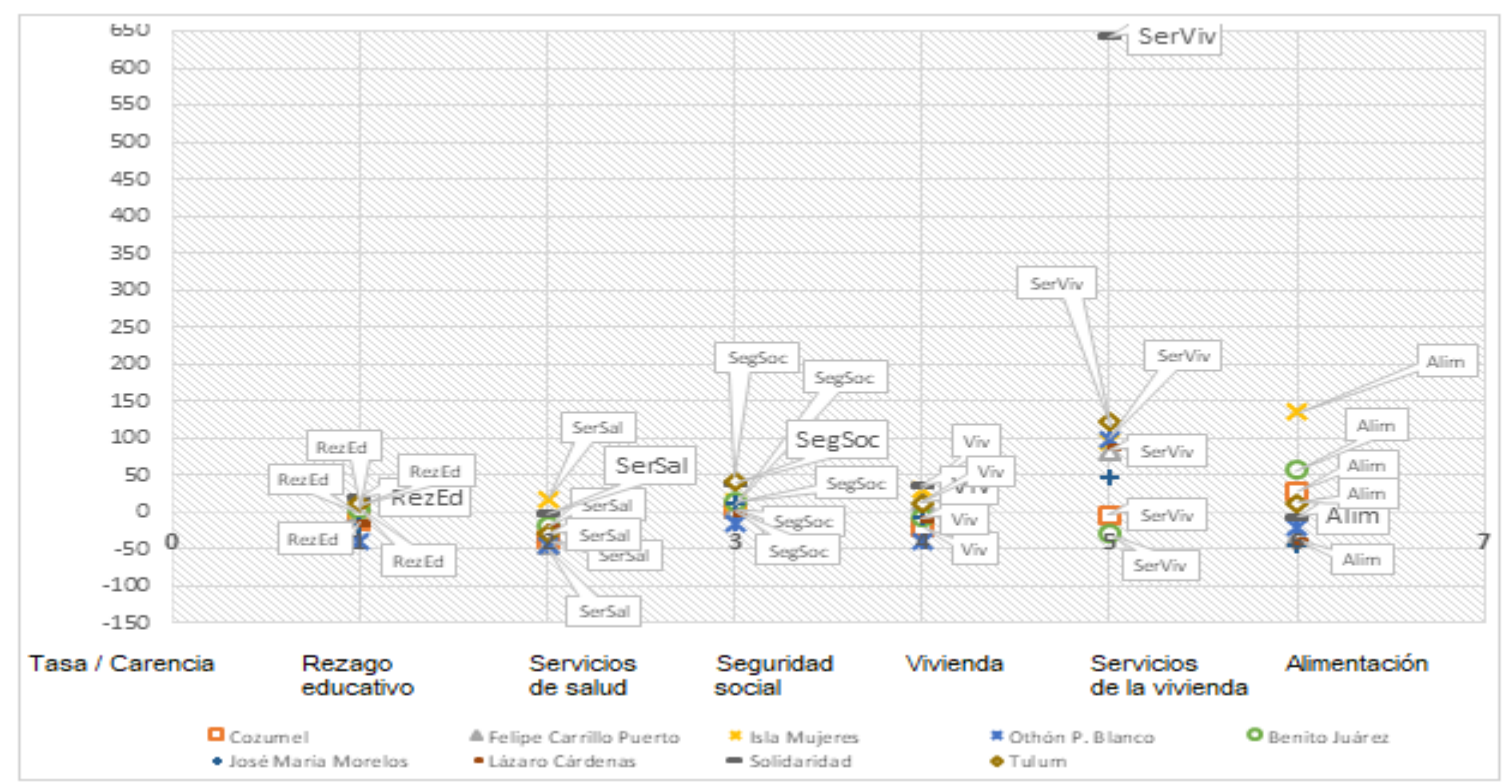

Fuente: Elaboración con datos de CONEVAL (2018)

En lo que refiere a las tasas de crecimiento de los indicadores de vulnerabilidad por ingreso o por carencia la gráfica 3 da cuenta de que Tulum y Lázaro Cárdenas registraron un incremento de cerca de $40 \%$ en el número de hogares que tienen menos de una carencia, lo cual es sumamente positivo. El único que tuvo problemas con este indicador fue Othón $\mathrm{P}$. Blanco que registró una caída de $-11.7 \%$. En lo que refiere a hogares que presentaron más

\footnotetext{
“Visión de Futuro" Año 17, Volumen N²4 N¹, Enero - Junio 2020 - Pág. 193 - 215

URL de la Revista: http://visiondefuturo.fce.unam.edu.ar/index.php/visiondefuturo/index

URL del Documento: http://visiondefuturo.fce.unam.edu.ar/index.php/visiondefuturo/issue/view/17 
de 3 carencias, Isla Mujeres fue el que mayor tasa de crecimiento presentó (68.3\%), seguido de solidaridad con $23 \%$ y Tulum con $17 \%$, mientras que municipios como Cozumel (-21.2\%) y Othón P. Blanco (-24.89\%) presentaron disminución en el número de hogares con más de tres carencias. En el rubro de hogares con ingreso por debajo de la línea de bienestar, Lázaro cárdenas (0.45\%), Solidaridad (8.3\%), Cozumel (18.79\%), Felipe Carrillo Puerto (23.69\%), Benito Juárez (29\%) y José María Morelos (30.1\%) tuvieron incremento del número de hogares en esta condición. De nuevo, el problema del combate a la pobreza, como se evidencia de lo anterior, no son las carencias, es el ingreso. Lo anterior se sostiene al observar la tasa de crecimiento de hogares con ingresos por debajo de la línea de bienestar mínimo, en ese sentido, los municipios indígenas Felipe Carrillo Puerto (37.8\%) y José María Morelos (34\%) fueron los municipios con mayor tasa de crecimiento. Cozumel y Lázaro Cárdenas también tuvieron tasas positivas con $17.8 \%$ y $16.5 \%$, respectivamente. Cancún tuvo la tasa negativa más pequeña, de apenas $-0.09 \%$, lo cual es de llamar la atención por la cantidad de empleo turístico que ahí se genera. Y el municipio que mayor número de hogares lograron mejorar su ingreso por encima de la línea de bienestar mínimo fue Isla Mujeres con -39.9\%.

La gráfica 4 y 5 dan cuenta del comportamiento que tuvieron las carencias promedio combinadas en población con pobreza y pobreza extrema, es decir, el CONEVAL por cada carencia registrada contabiliza las carencias promedio que se tienen además de la que analiza. Por ejemplo quien tiene carencia de rezago educativo puede tener $\mathrm{n}$ carencias promedio extras. En ese sentido la gráfica 4 y 5 terminan por reforzar la idea de que el mejoramiento de las condiciones de pobreza y pobreza extrema en México y Quintana Roo se dio solamente a través de solventar las carencias y no de un real mejoramiento del ingreso. De hecho todos los municipios tuvieron disminución de carencias promedio, excepto Solidaridad.

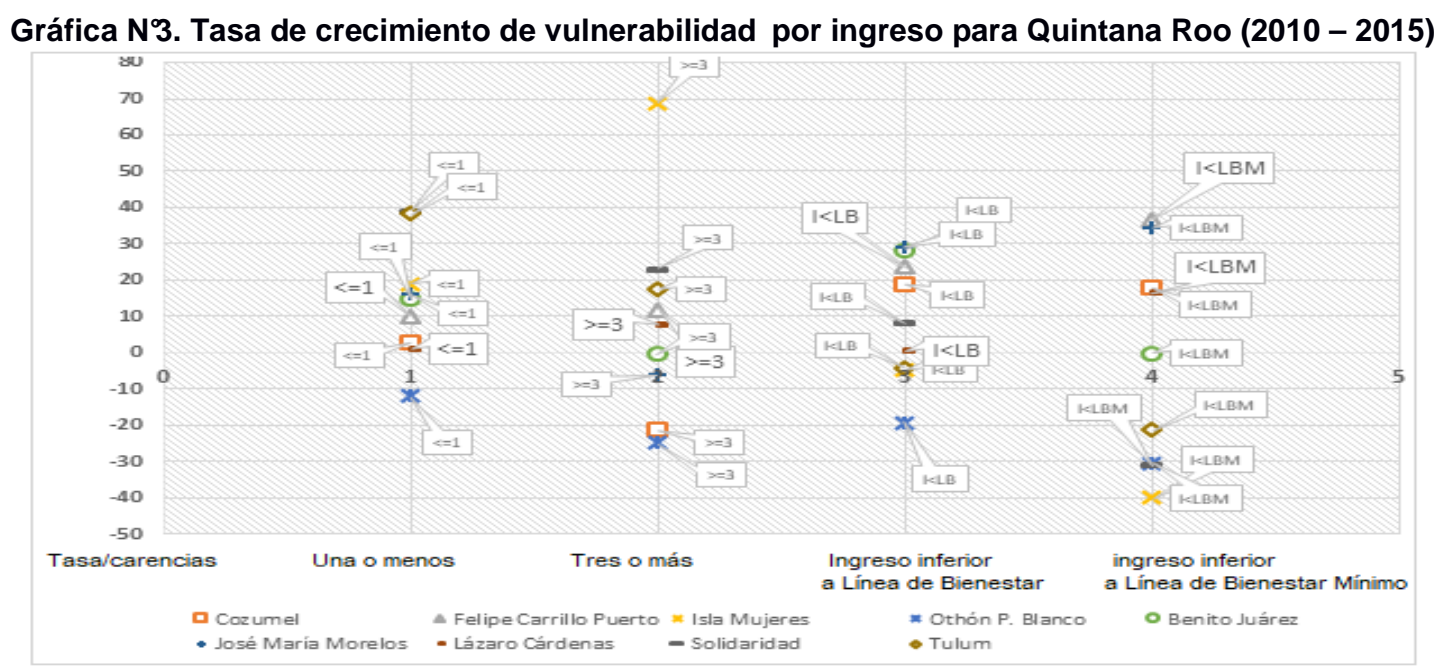

Fuente: Elaboración con datos de CONEVAL (2018)

\footnotetext{
"Visión de Futuro" Año 17, Volumen N² 24 N¹, Enero - Junio 2020 - Pág. 193 - 215

URL de la Revista: http://visiondefuturo.fce.unam.edu.ar/index.php/visiondefuturo/index

URL del Documento: http://visiondefuturo.fce.unam.edu.ar/index.php/visiondefuturo/issue/view/17

ISSN 1668 - 8708 - Versión en Línea

E-mail: revistacientifica@fce.unam.edu.ar
} 
Gráfica N4. Carencias promedio en población en sit uación de pobreza en Quintana Roo (2010-2015)

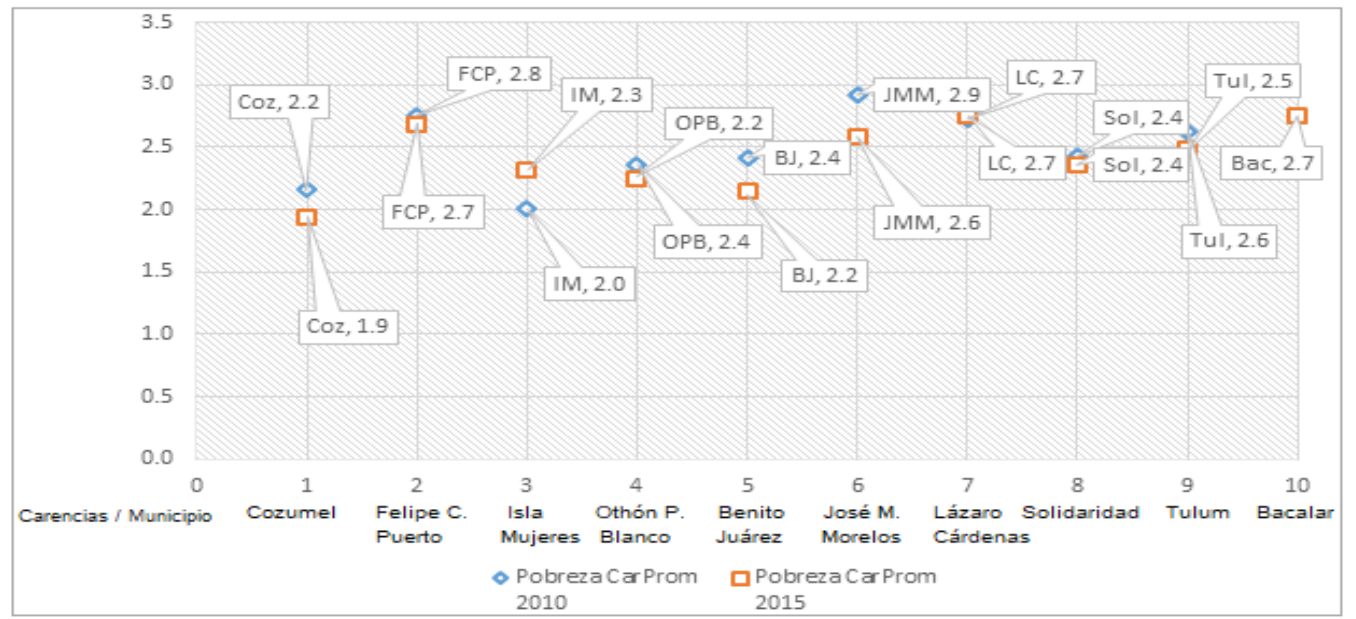

Fuente: Elaboración con datos de CONEVAL (2018)

Gráfica N5. Carencias promedio en población en pob reza extrema en Quintana Roo (2010-2015)

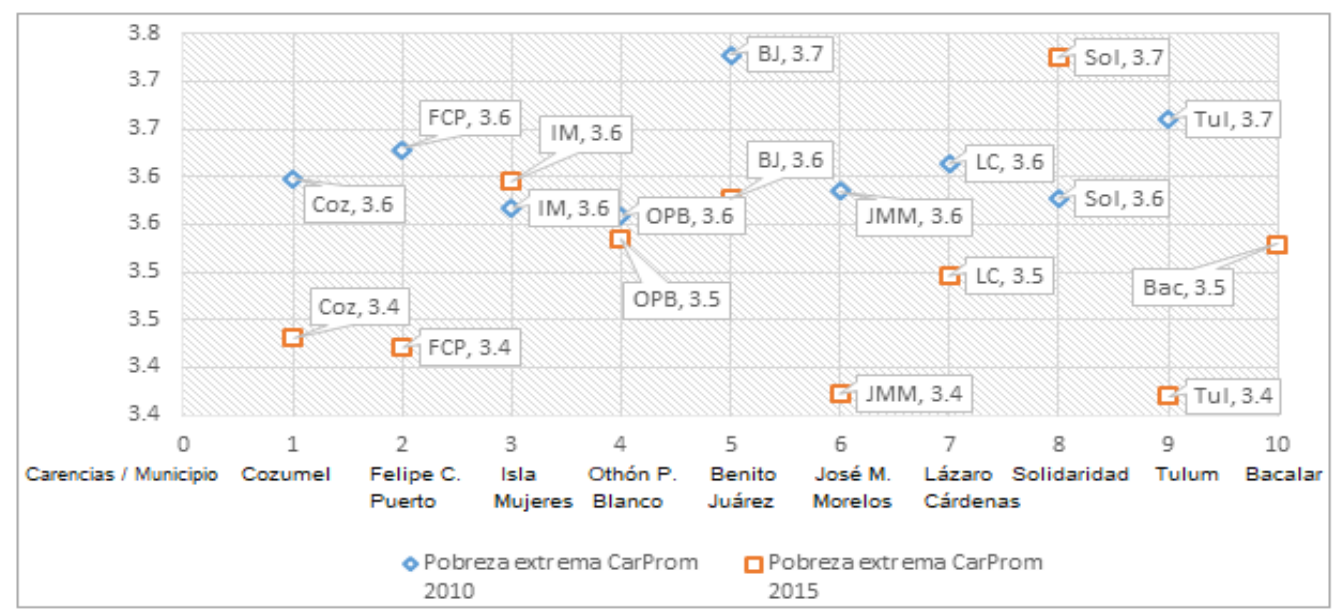

Fuente: Elaboración con datos de CONEVAL (2018)

Gráfica N6. Carencias promedio en población en pob reza moderada en Quintana Roo (2010-2015)

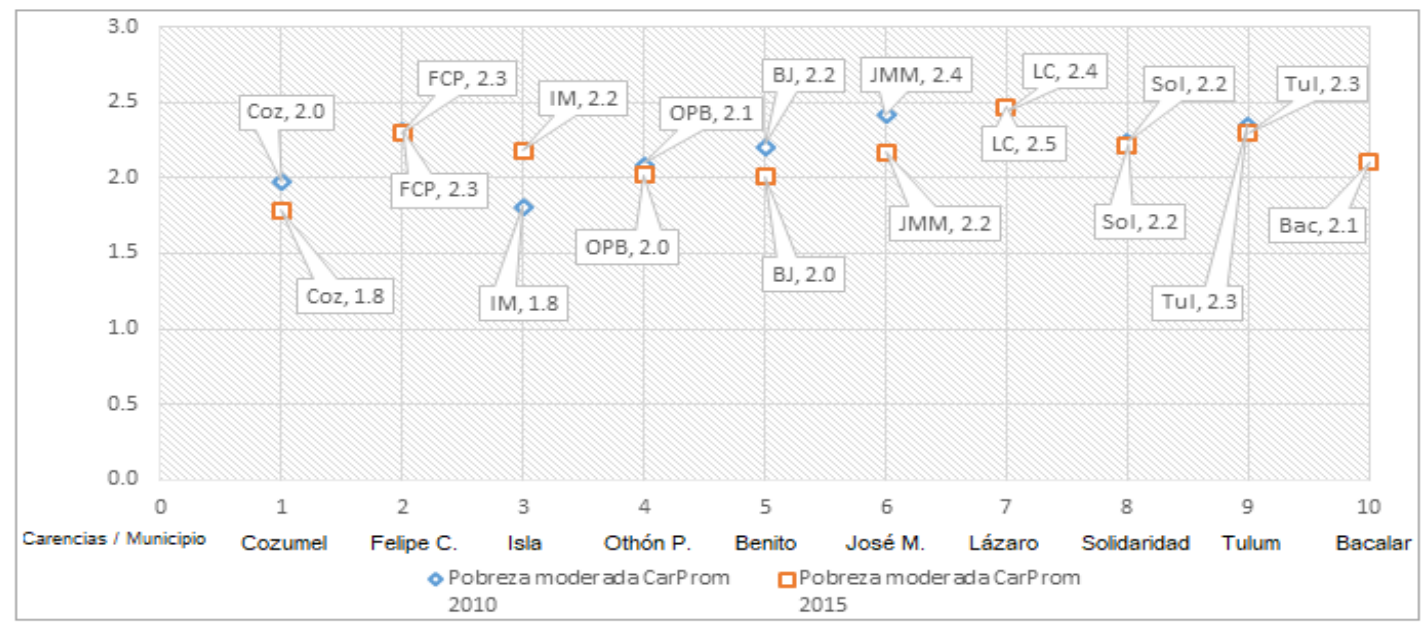

Fuente: Elaboración con datos de CONEVAL (2018)

"Visión de Futuro" Año 17, Volumen Nº 24 Nº1, Enero - Junio 2020 - Pág. 193 - 215

URL de la Revista: http://visiondefuturo.fce.unam.edu.ar/index.php/visiondefuturo/index

URL del Documento: http://visiondefuturo.fce.unam.edu.ar/index.php/visiondefuturo/issue/view/17

ISSN 1668 - 8708 - Versión en Línea

E-mail: revistacientifica@fce.unam.edu.ar 


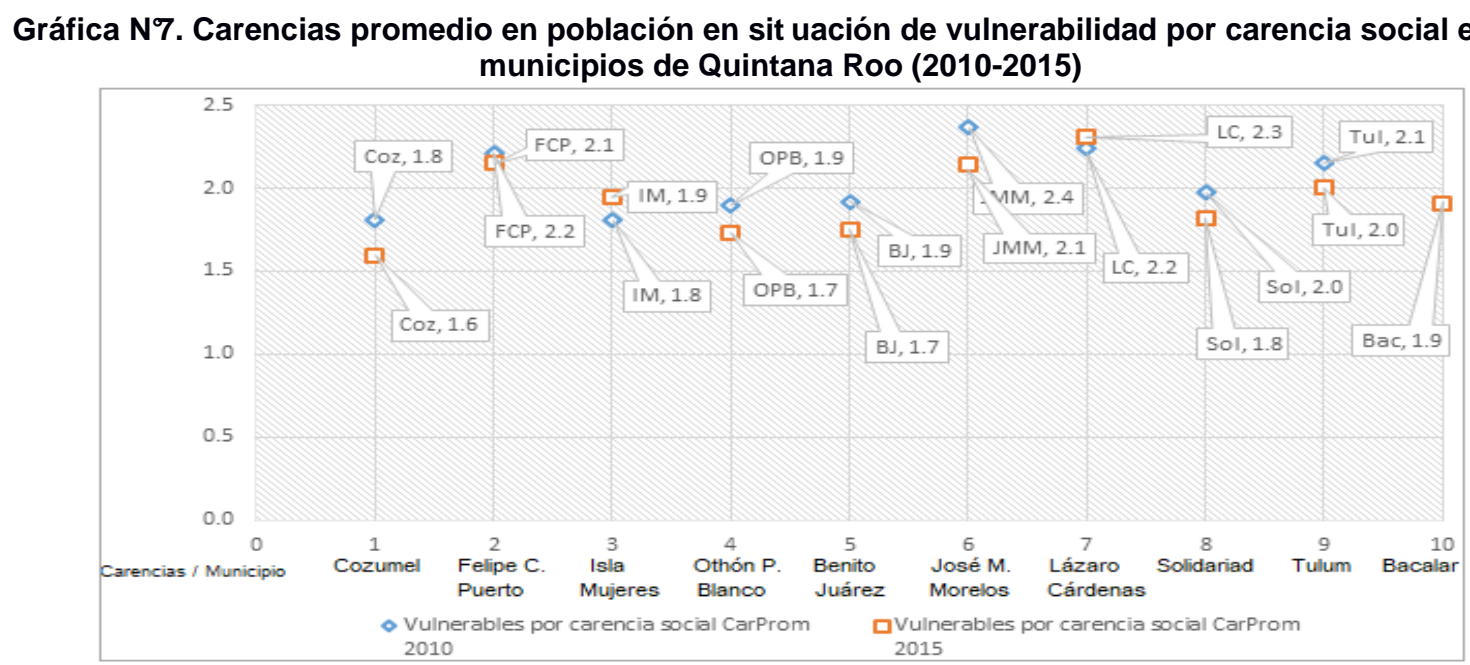

Fuente: Elaboración con datos de CONEVAL (2018)

En lo que refiere al ingreso como la variable complementaria para la medición, identificación y clasificación de la pobreza, se tiene que en la gráfica 8 se aprecia la estructura del ingreso para el periodo 2010-2016, en él se observa claramente que el ingreso proveniente del trabajo en 2016 tiene un porcentaje de participación apenas superior al de 2010 con una notoria caída en 2014; mientras que la proporción del ingreso proveniente de rentas aumentó en el periodo de estudio, registrando la misma caída en 2014 que el ingreso por trabajo. Los ingresos por transferencias llenaron el hueco en la estructura del ingreso corriente que los ingresos por trabajo y renta dejaron en 2014.

Gráfica N8. Estructura del ingreso en Quintana Roo (2010-2016)

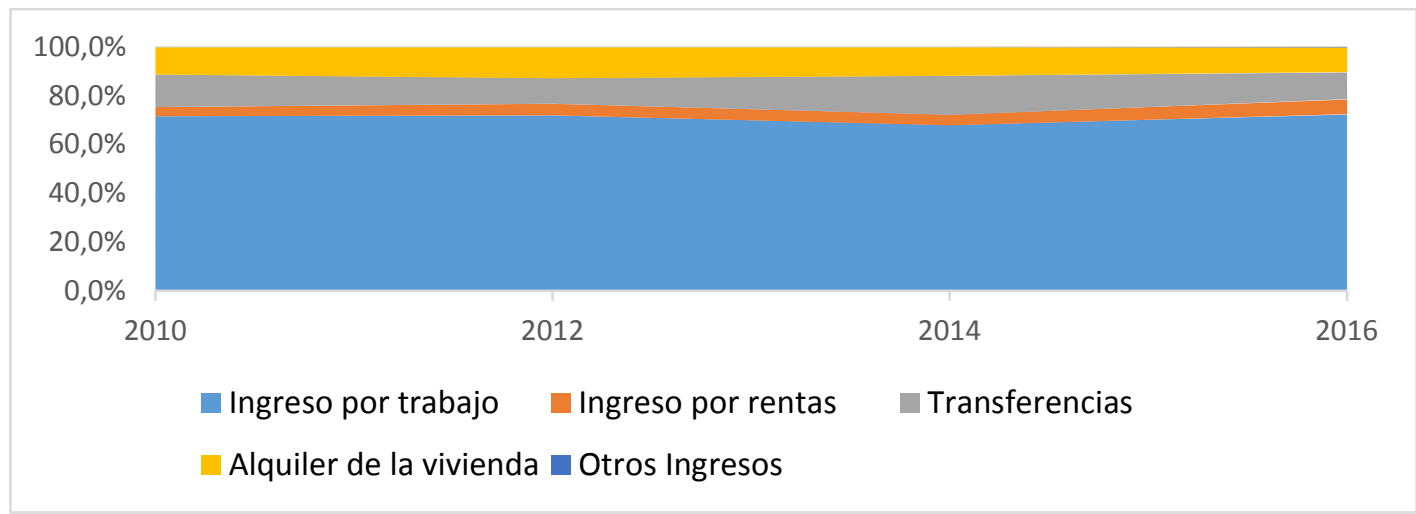

Fuente: Elaboración propia con datos de INEGI (2011, 2013, 2015b, 2017)

La gráfica 9, donde los datos de ingreso corriente se acomodaron por año del menor al mayor, resulta clave para el análisis pues ésta da cuenta de que el ingreso corriente, es decir, la suma de todos los ingresos que percibe un hogar, no ha tenido gran variación en el periodo

\footnotetext{
"Visión de Futuro" Año 17, Volumen N²4 N¹, Enero - Junio 2020 - Pág. 193 - 215

URL de la Revista: http://visiondefuturo.fce.unam.edu.ar/index.php/visiondefuturo/index

URL del Documento: http://visiondefuturo.fce.unam.edu.ar/index.php/visiondefuturo/issue/view/17

ISSN 1668 - 8708 - Versión en Línea

E-mail: revistacientifica@fce.unam.edu.ar
} 
2010-2016, de hecho, de no ser por el par de outlayers en 2014, que de paso evidencian desigualdad en los ingresos, la tendencia es a permanecer estático o disminuir. Si se eliminasen los datos máximos en las 4 observaciones, el gran grueso de los hogares tiene ingresos similares.

Gráfica N9. Ingreso Corriente en Quintana Roo (2010-2016)

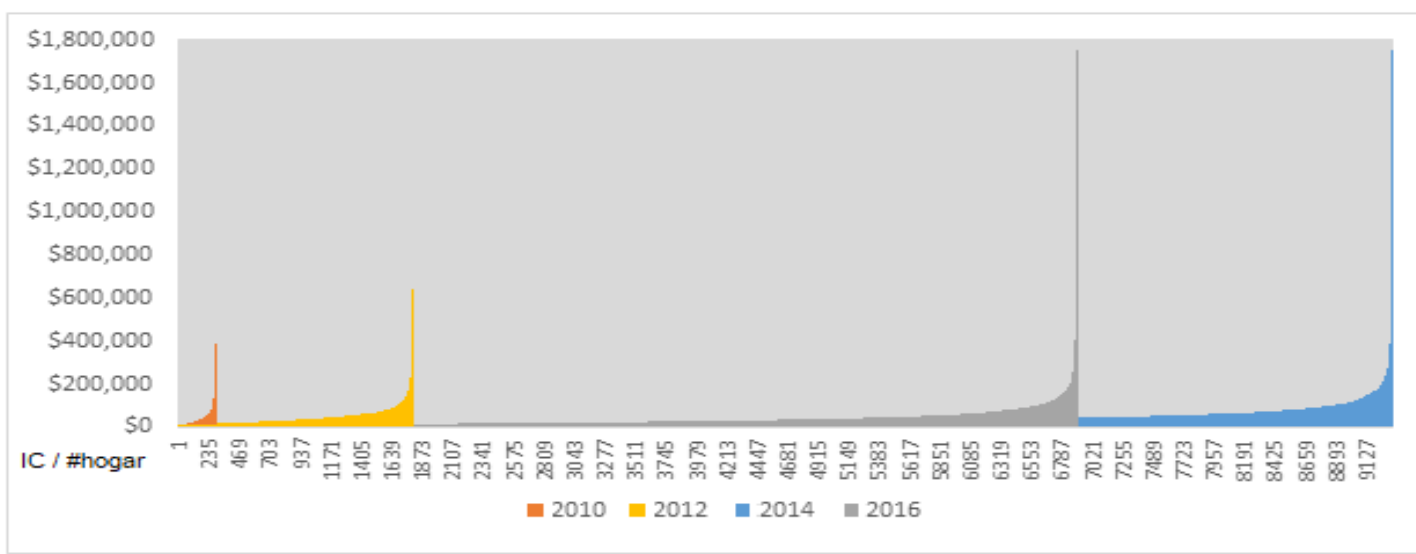

Fuente: Elaboración propia con datos de INEGI (2011, 2013, 2015b, 2017)

\section{CONCLUSIÓN}

Como se ilustra en este trabajo, es evidente que, al menos en el caso de Quintana Roo, la disminución de la pobreza está más atribuida a cuestiones referentes a la superación de las carencias que se definen en los Lineamientos y Criterios para la Definición, Identificación y Medición de la Pobreza que el CONEVAL publicó en el Diario Oficial de la Federación y no de una mejora evidente en lo relativo al ingreso. Esto es, que los dos millones de pobres extremos que el ex Secretario de Hacienda y Crédito Público y ex candidato a la presidencia, José Antonio Meade, anunció que habían desaparecido, lo hicieron sólo por superación de carencias. Es decir, dejaron la pobreza extrema para ser pobres o en el mejor de los casos vulnerables por ingreso.

El problema de lo anterior es que como se evidenció en el trabajo, la cantidad de pobres no disminuyó y la cantidad de vulnerables por ingreso aumentó. Esto soporta la afirmación de que la pobreza se superó solamente a partir de carencias y no de la mejora en el ingreso. Será interesante hacer una nueva evaluación de datos de pobreza en 2021 cuando el CONEVAL genere su informe quinquenal y el INEGI haya presentado los datos de la ENIGH 2018 y 2020. Esos datos permitirán conocer de manera aún más profunda los resultados de las políticas de combate a la pobreza que han implementado los gobiernos neoliberales de los últimos dos sexenios en México. 
Se espera por un lado que este trabajo contribuya a la discusión sobre la situación de la pobreza en México, especialmente por que aborda dicho fenómeno desde una perspectiva estatal; y por otro lado, a que se urja a los tomadores de decisiones públicas a tener información que les ayude a entender desde la perspectiva académica las fallas que han tenido en el diseño de las políticas públicas. Como en este caso que se intentó solucionar el problema de la pobreza a través de la superación de carencias y no de la mejora en el ingreso.

\section{REFERENCIAS}

Aguilar, A.; Caamal, I. y Portillo, M. (2018). Intensidades de pobreza multidimensional en México a nivel municipal. Revista mexicana de ciencias agrícolas, 9(1): 251-258.

Alkire, S. y Foster, J. (2007). Recuento y medición multidimensional de la pobreza. Oxford, OPHI Working Papers Series.

Altmir, O. (1979). Dimensión de la pobreza en América Latina. Santiago, CEPAL.

Banco Mundial (1992). La medición de la pobreza, Comercio Exterior, 42(4), 323-325.

Barajas, G. (2018). "La política de atención a la pobreza del gobierno de Enrique Peña Nieto: reflexiones a partir del análisis histórico y presupuestal", Revista de Estudios Interculturales, Núm. 7: 83-101.

Barrera, M. y Reyes, O. (2013). Pobreza y transferencias monetarias en comunidades mayas de México: José María Morelos y Sabán, Quintana Roo, 2011, Equilibrio económico, 9 (2): 201-228.

Barrera, M. (2018). Pobreza extrema de mujeres indígenas en México. Estudio de caso para la Zona Maya de Quintana Roo. Ciencia e Interculturalidad, 22(1), 89-105.

Boltvnik, J. (1990). Pobreza y necesidades básicas. Conceptos y métodos de medición, Caracas, Proyecto Regional para la Superación de la Pobreza-PNUD.

Boltvinik, J. (2012). Treinta años de medición de la pobreza en México. Una mirada desde Coplamar. Estudios Sociológicos, 83-110.

Camacho, R. (2015). Urbanización turístico-costera desigual en Playa del Carmen, Quintana Roo (México), Geographos, 6(77): 107-134

Campos, R. y Rodas, J. (2019). Desigualdad en el ingreso: posibilidades de acción pública. Economíaunam, 16(46), 251-261.

Canto, R. (2019). ¿Distribuir o redistribuir? Pobreza, desigualdad y política pública en México. Economía, Sociedad y Territorio, XVIII (59), 1181-1211

Castillo, O. y Méndez, O. (2017). Los desarrollos turísticos y sus efectos medioambientales en la Riviera Maya, 1980-2015. Quivera Revista de Estudios Territoriales, 19 (2): 101118.

\footnotetext{
"Visión de Futuro" Año 17, Volumen N² 24 N¹, Enero - Junio 2020 - Pág. 193 - 215

URL de la Revista: http://visiondefuturo.fce.unam.edu.ar/index.php/visiondefuturo/index

URL del Documento: http://visiondefuturo.fce.unam.edu.ar/index.php/visiondefuturo/issue/view/17 
CONEVAL. 2016. Memorias del CONEVAL 2006-2016. México, CONEVAL.

CONEVAL (2018). Glosario [en línea] Consultado el 9/11/18 https://www.coneval.org.mx/Medicion/Paginas/Glosario.aspx

COPLAMAR (1982), Macroeconomía de las necesidades esenciales, México, Siglo XXI.

COPLAMAR (1982a), Alimentación, vol. 1, Serie Necesidades esenciales en México: situación y perspectivas al año 2000, México, Coplamar, Siglo XXI.

COPLAMAR (1982b), Educación, vol. 2, Serie Necesidades esenciales en México, México, Siglo XXI.

COPLAMAR (1982c), Vivienda, vol. 3, Serie Necesidades esenciales en México, México, Siglo $\mathrm{XXI}$.

COPLAMAR (1982d), Salud, vol. 4, Serie Necesidades esenciales en México, México, Siglo $\mathrm{XXI}$.

COPLAMAR (1982e), Geografía de la marginación, vol. 5, Serie Necesidades esenciales en México, México, Siglo XXI.

Damian, A. (2007). Los problemas de comparabilidad de la ENIGH y su efecto en la medición de la pobreza. Papeles de población. 13(51), 111-146.

Diario Oficial de la Federación (2010). Lineamientos y criterios generales para la definición, identificación y medición de la pobreza [en línea] Consultado el 10/06/2018 http://www.dof.gob.mx/nota detalle popup.php?codigo=5146940

Feres, J. y Mancero, X. (2001). El método de las Necesidades Básicas Insatisfechas (NBI) y sus aplicaciones en América Latina, Santiago, CEPAL.

González, E. D., y Barragán, E. H. T. (2018). Pobreza y política social en México y estados de la frontera norte. Revista Análisis Económico, 27(64), 23-46.

Gordon, D.; Nandy, S.; Pantazis, C.; Pemberton, S. y Towsend, P. (2003). Child poverty in the developing world, Bristol. Policy Press.

Herrera, A. y Castro, H. (2018). Nuevas alternativas para combatir la pobreza en México: caso San Andrés Cholula, Transitare, 4(1): 14-38.

INEGI (2011). ENIGH 2010. Nueva construcción [en línea] Consultado el 10/06/2018 http://www.beta.inegi.org.mx/proyectos/enchogares/regulares/enigh/nc/2010/default.ht $\underline{\mathrm{ml}}$

INEGI (2013). ENIGH 2010. Nueva construcción [en línea] Consultado el 10/06/2018 http://www.beta.inegi.org.mx/proyectos/enchogares/regulares/enigh/nc/2012/default.ht $\underline{\mathrm{ml}}$ 
INEGI (2014). México-Encuesta Nacional de Ingresos y Gastos de los Hogares 2014 [en línea] Consultado el $16 / 06 / 2019$

http://www3.inegi.org.mx/rnm/index.php/catalog/164/sampling

INEGI (2015). Encuesta Nacional de Ingresos y Gastos de los Hogares. ENIGH 2014. Nueva construcción de ingresos y gastos. Diseño conceptual y definición de categorías y variables. Aguascalientes, México, INEGI.

INEGI (2015b). ENIGH 2010. Nueva construcción [en línea] Consultado el 10/06/2018 http://www.beta.inegi.org.mx/proyectos/enchogares/regulares/enigh/nc/2014/default.ht $\underline{\mathrm{ml}}$

INEGI (2017). ENIGH 2010. Nueva construcción [en línea] Consultado el 10/06/2018 http://www.beta.inegi.org.mx/proyectos/enchogares/regulares/enigh/nc/2016/default.ht $\underline{\mathrm{ml}}$

INEGI (2018). Glosario [en línea] Consultado el 7/11/18 http://www3.inegi.org.mx/sistemas/sisept/glosario/default.aspx?t=mhog24\&e=00\&i

Ley General de Desarrollo Social (2004). Disponible en http://www.diputados.gob.mx/LeyesBiblio/pdf/264 250618.pdf

Planning Institute of Jamaica (2007). The poverty-enviroment nexus: Establishing an approach for determining special development areas in Jamaica. Kingston, PIOJ.

Reglamento de la Ley General de Desarrollo Social (2004). Disponible en http://www.diputados.gob.mx/LeyesBiblio/regley/Reg LGDS.pdf

Reyes, O., \& Barrera, M. (2014). Estructura y desigualdad del ingreso en la zona maya de Quintana Roo. Un estudio de caso para las comunidades de José María Morelos y Sabán en Quintana Roo, México, 2011. Revista de Economía, 31(82), 113-130.

Sen, A. (1976). Elección colectiva y bienestar social, Madrid, alianza.

Sen, A. (2000). Desarrollo y libertad, Barcelona, Planeta.

Székely , M., López , L.., Meléndez,, Á., Rascón, E., y Rodríguez , L. (2007). Poniendo a la pobreza de ingresos y a la desigualdad en el mapa de México. Economía Mexicana. Nueva Época, XVI (2), 239-303.

Torres, F. y Rojas, A. (2015). Política económica y política social en México: Desequilibrios y saldos, Revista Problemas del Desarrollo, 182 (46): 41-65.

Toscana, A. y Oscar, R. (2018). Repensar la ruralidad: la vulnerabilidad socioeconómica de los hogares rurales de la zona Maya de Quintana Roo, México: una caracterización en función de su estructura económica y la distribución del ingreso, en Hoyos, G.; Serrano, O., Serena, E. y Mora, M. (Coords.) CIUDAD, GÉNERO, CULTURA Y EDUCACIÓN EN LAS REGIONES. México, Universidad Nacional Autónoma de México y Asociación

\footnotetext{
"Visión de Futuro" Año 17, Volumen N² 24 Nº 1, Enero - Junio 2020 - Pág. 193 - 215

URL de la Revista: http://visiondefuturo.fce.unam.edu.ar/index.php/visiondefuturo/index

URL del Documento: http://visiondefuturo.fce.unam.edu.ar/index.php/visiondefuturo/issue/view/17

ISSN 1668 - 8708 - Versión en Línea

E-mail: revistacientifica@fce.unam.edu.ar
} 
Mexicana de Ciencias para el Desarrollo Regional A.C. Volumen V de la Colección:

Nuevos escenarios mundiales, repercusiones en México y potencialidades, pp. 1-25.

UNICEF (2000). Poverty reduction begins with children. Nueva York, UNICEF.

\section{REFERENCIAS BIOGRÁFICAS}

\section{Miguel Angel Barrera Rojas}

Doctor en Geografía por la Universidad de Quintana Roo, Profesor Investigador de Carrera en la División de Ciencias Políticas y Humanidades de la Universidad de Quintana Roo, Chetumal. Sus líneas de investigación actualmente son pobreza, desigualdad, marginación, política social. 